\title{
Fitness and Health Status among German Senior Managers: A Cross-sectional Analysis
}

\author{
By Diana Jedlicka* \\ Klaus-Michael Braumann ${ }^{+}$ \\ Martin Halle \\ Katja Petrowski \\ Hans-Georg Predel
}

\begin{abstract}
Epidemiological research on the general population demonstrated that physical activity and aerobic fitness significantly lowered cardiovascular risk. The objective of this study was to specify medical data on the broad basis of various psycho-physiological parameters concerning health and fitness among senior managers. This retrospective cross-sectional analysis of 110 managers includes the assessment of medical data, blood tests, a bicycle exhaustion test, a health questionnaire and the calculation of the cardiovascular risk score. Subjects had an average BMI of $26.1 \mathrm{~kg} / \mathrm{m} 2$ (51\% overweight), 43\% arterial hypertension and 12\% presented a metabolic syndrome. No subject had manifest diabetes, however $41 \%$ were prediabetic. The majority had a sufficient cardiopulmonary capacity. Health questionnaires mostly revealed positive selfestimations. Managers revealed a low-risk for future cardiovascular events with mean Carrisma risk values (based on Procam) of 2.6\%. The self-estimated health status and measured personal fitness significantly influenced Carrisma with 23\%, measured via a stepwise regression model. Except for hypertension, prediabetes and overweight values in some individuals, the cohort of this study revealed a good health and fitness status compared to the overall population in Germany, yet demonstrated the need for systematic screening programs in high-performing managers. Longitudinal studies are required to further investigate this research topic.
\end{abstract}

Keywords: Cardiovascular risk, Executives, Health, Managers, Physical fitness

\section{Introduction}

In a rapidly changing corporate environment, it is more necessary than ever to perform permanently at high levels. Organizational parameters and the attitude towards health promotion in companies are determining factors for employers and employees regarding their job stress, stress report, performance and wellbeing (Jamal \& Baba 2000, Jung et al. 2012, Lin \& Lin 2014). Managers and executives represent a group dealing with great pressure, consistent high stress and permanent availability even after the official working hours (Plante \& Bouchard 1996), leading to a higher risk of depression (Hsu et al. 2016). They not

\footnotetext{
*Research Assistant, Institute of Cardiology and Sports Medicine, German Sport University Cologne, Germany.

"Professor \& Head, Department of Sports and Movement Medicine, Faculty of Psychology and Movement Science, University of Hamburg, Germany.

"Professor \& Head, Center for Prevention and Sports Medicine, Technical University Munich, Germany.

${ }^{+}$Professor, Institute for Movement Therapy and Movement-Oriented Prevention and Rehabilitation, German Sport University Cologne, Germany.

'Professor \& Head, Institute of Cardiology and Sports Medicine, German Sport University Cologne, Germany.
} 
only serve as the classic role of the "boss", but symbolize also a role model and work as multiplicators. Furthermore, from an economic perspective, if executives are absent and fail to appear at work, it rapidly leads to high costs for companies.

Moreover, it is well known that there is a clear correlation between socioeconomic status and health (Robert Koch-Institut 2015). Thus, it can be assumed that managers and executive employees might be healthier than the other employees. In fact, studies do not provide consistent results (Meifert \& Kesting 2004, Hsu et al. 2016, Kennedy 2003). The group of managers and executives is particularly affected by stress, permanent availability and a high responsibility concerning their own employees. For this reason, health and fitness of managers are very important for the entire company, which has already been stated by Lundqvist et al. (2012). They concluded that managers' leadership, health and work conditions are reciprocally related to each other, and a productive and healthy workplace is facilitated by focusing on managers' conditions for leadership, their health and their work conditions.

\section{Literature Review}

Several research working groups have already reported about the health of employees and employers, stating that chief executive officers (CEO) were mostly found to be in a poor physical condition with about one-fourth reporting having never exercised since their childhood (Kennedy 2003). Heidrick and Struggles (2014) collected data of 645 managers about how they make use of medical checkup examinations. They concluded that $50 \%$ of them undergo medical check-ups regularly ( $\geq 1$ times per year) and an almost equally-sized group goes only irregularly (once in 5 years). Data reveal that even though managers work many hours with permanent stress, they still have a well-established health consciousness, even though theory and reality might often diverse greatly.

The results of the Kienbaum study showed that more than $50 \%$ of managers regularly complain about disorders of the body, such as back and joint pain, sleep disorders or heart stumbling. Executives under the age of 35 are particularly affected. In addition, about $50 \%$ of managers attain less than 1,000 meters of movement per day and spend less than 30 minutes a day outdoors (Hunziger \& Kesting 2004). Zimber et al. (2015) reported in their study "Mental Health of Managers" that executives are at an increased risk of mental illness. Other studies showed that according to the Body Mass Index (BMI) definition, managers are often overweight (48\%), and yet they are still healthier than the average German adult (Heidrick \& Struggles 2014).

To the best knowledge of the authors, this is the first study to investigate health and quality of life including specific practical examinations and objective exercise tests in a cohort of business managers. So far, there exist only studies about managers revealing information about classical parameters, such as weight, obesity, blood values or psychological variables (questionnaires for burn-out, selfperception of leadership competencies, etc.) (Conrads 2015, Grannemann \& Seele 2016, Hunziger \& Kesting 2004, Zimber et al. 2015). Masarei et al. (1982) measured physical work capacity, defined as endurance fitness, on a bicycle 
ergometer among business managers. However, in their research study, the heart rate recorded in the last minute of each segment was used to estimate the work possible at $\mathrm{HR}_{170}$, meaning that subjects might not have reached their own specific physical exhaustion level. Moreover, the exact workload achieved after each 3 minute interval was not described in detail in the methods of the examinations.

To date, there has been little change in cardiovascular risk (cv) factors and their place among the leading causes of death (World Health Organization 2014). In 2008, Germany spent 254.3billion euros on prevention, treatment, rehabilitation and care of illnesses and accidents. Of this total, cardiovascular diseases accounted for the highest healthcare costs, around 37 billion euros (14.5\%) (Statistisches Bundesamt 2015). In 2012, the world's largest numbers of deaths were caused by ischemic heart diseases (including heart attacks), strokes and chronic obstructive pulmonary disease (COPD), all which are diseases influenced by cv risk factors. In 2012 alone, more than 17 million people died of it worldwide (World Health Organization 2014). In 2013, nearly 355,000 people died of cv disease in the Federal Republic of Germany. That was almost $40 \%$ of all deaths (Statistisches Bundesamt 2015).

So far, despite this background, there is no data on executives regarding cv risk on the basis of so-called risk scores. There are various score systems (Gohlke 2012, Gohlke et al. 2007, Keil et al. 2005, Kones 2011) for predicting the risk or risk stratification of death or non-fatal coronary events over the next few years. The so-called CARRISMA risk value, calculated on the basis of the PROCAM score (CARdiovascular RIsk MAnagement in primary prevention), provides information about the risk of developing a non-fatal coronary event within the next 10 years. It reflects a risk score as an advanced assessment tool integrating additional information concerning lifestyle, e.g. physical activities and smoking patterns, to predict the risk for a non-lethal cv event in the next 10 years. So far, the Carrisma algorithm has not been used in business-managers in other research studies (Gohlke et al. 2007).

The aim of this cross-sectional study was to specify and evaluate medical data (for details, see methods section) on the basis of various psycho-physiological parameters concerning health and fitness in senior business managers. The investigation is a state analysis to present current data on this topic in order to reduce the existing scientific gap. Further, in this study we evaluate the cv risk for non-lethal events in the next 10 years among managers and analyze if there are additional, predictive parameters to prognosticate $\mathrm{cv}$ risk profiles. Through this, it is our hope that risk stratification is more precise in the future.

\section{Methodology}

\section{Study Overview}

This cross-sectional study was a retrospective analysis of medical data collected between 2012 and 2016 through medical health check-ups. Besides the generation of medical data, subjects had to complete an exercise test on a bicycle ergometer until subjective exhaustion. 


\section{Subjects}

A total of 110 executives (98 male, 12 female; age: $45.6 \pm 6.8$ years; height: $181.3 \pm 7 \mathrm{~cm}$; body weight $85.7 \pm 13.8 \mathrm{~kg}$; Body mass index (BMI): $26.1 \pm 3.4$ $\mathrm{kg} / \mathrm{m}^{2}$ ) were recruited via worksite health management projects with each of the following Universities. All subjects were senior managers of different international large enterprises with 850-330,000 employees and were working in Germany. Data were collected between 2012 and 2016 and evaluated within this study. Inclusion criteria were the status of a manager or executive, working at first or second hierarchy, and senior management level. Fifty-four executives were examined at the German Sport University Cologne, Germany, Institute of Cardiology and Sports Medicine, 24 at the University of Hamburg, Faculty of Psychology and Human Movement Science and 32 at the Centre for Preventive and Sports Medicine, Technical University of Munich. Prior to performance tests, all subjects were examined medically.

\section{Ethics}

The study was approved by the local ethics committee of the German Sport University Cologne, Germany (Number: 099-2016) and has therefore been performed in accordance with the ethical standards laid down in the 1975 Declaration of Helsinki. All subjects provided informed written consent prior to participation in the study and agreed to anonymous use of their data. The participation was voluntary. Withdrawal was possible at any time without any disadvantages for the participant.

\section{Laboratory Parameters}

For the assessment of laboratory parameters, a blood sample was drawn under fasting conditions. The following parameters were analysed within the serum analyses: fasting blood glucose, $\mathrm{HbA}_{1 \mathrm{c}}$, blood lipids (total cholesterol, low-density lipoprotein (LDL), high-density lipoprotein (HDL), triglycerides). Blood lipid values and fasting blood glucose were analysed via Roche Hitachi Cobas Mira Plus Analyzer (Roche Diagnostics, F. Hoffmann-La Roche AG, Basel, Switzerland). $\mathrm{HbA}_{1 \mathrm{c}}$ was measured in an external laboratory, Synlab (Leverkusen, Germany) with the G8 HPLC Analyzer (Tosoh Bioscience, Inc., San Francisco, USA).

\section{Pulse Wave Diagnostics and Blood Pressure}

Pulse wave measurements were performed via the Mobil-O-Graph® NG (I.E.M. GmbH, Stolberg, Germany) and illustrated graphically with the software program "Hypertension Management Software Client-Server" as a validated method (Milatz et al. 2015). Blood pressure was obtained by an automated procedure (M500, Omron Healthcare, Kyoto, Japan). 


\section{Reference Values}

The following parameters were determined as risk factors within the study, when: Hypertension $>140 />90 \mathrm{mmHg}$ (Chobanian et al. 2003), prediabetes: fasting blood glucose $100-126 \mathrm{mg} / \mathrm{dl}$ and/or $\mathrm{HbA}_{1 \mathrm{c}}$ from $5.7-6.45 \%$, diabetes: fasting blood glucose $>126 \mathrm{mg} / \mathrm{dl}$ and/or $\mathrm{HbA}_{1 \mathrm{c}}>6.45 \%$ (World Health Organisation 2015a, Little \& Sacks 2009). Overweight and obesity (defined via BMI): underweight $<18.5 \mathrm{~kg} / \mathrm{m}^{2}$, normal weight $18.50-24.99 \mathrm{~kg} / \mathrm{m}^{2}$, overweight $25 \mathrm{~kg} / \mathrm{m}^{2}-29.99 \mathrm{~kg} / \mathrm{m}^{2}$, obesity $\geq 30.0 \mathrm{~kg} / \mathrm{m}^{2}$ (World Health Organisation $2015 \mathrm{~b}$ ). The metabolic syndrome was described elsewhere as a combination of different cv risk factors (International Diabetes Federation 2006, Gupta \& Gupta 2010) and diagnosed when: elevated waist circumstance and/or BMI $>30 \mathrm{~kg} / \mathrm{m}^{2}$ plus two factors of raised triglycerides, HDL-cholesterol, hypertension, fasting blood glucose, or $\mathrm{HbA}_{1 \mathrm{c}}>5.6 \%$. For standardized conditions and comparability of the results, all medical and performance tests were performed identically in all participating centers. Data accuracy and reliability were enhanced by experienced, trained, medical staff in the centers, who measured the parameters.

\section{Performance Diagnostics}

According to the international guidelines for activity recommendations (World Health Organization 2010), adults are encouraged to be moderately active for at least 150 minutes or vigorously active for at least 75 minutes, in addition to strength training, at least twice per week. Physical work capacity (PWC), referred to as personal fitness, was assessed by an incremental exhaustion test on a bicycle ergometer Ergometrics 900 (Ergoline GmbH, Bitz, Germany) and measured in watts. Cardiac exhaustion was measured via heart rate with the standard formula: 200 minus age (Rost \& Hollmann 1982, Tanaka et al. 2001). Reference values for healthy untrained people vary depending on age and gender (Fletcher et al. 1995).

Endurance performance is defined as absolute $\mathrm{VO}_{2} \max \left(\mathrm{min}^{-1}\right)$ and relative $\mathrm{VO}_{2} \max \left(\mathrm{ml} \mathrm{min}^{-1} \mathrm{~kg}^{-1}\right)$, respectively. The evaluation of data was carried out using the software AMEDTEC ECGpro® v.3.66 (AMEDTEC Medizintechnik Aue $\mathrm{GmbH}$, Aue, Germany). $\mathrm{VO}_{2} \max$ was measured via a spiroergometry $\left(\mathrm{ZAN}^{\mathrm{TM}_{\circledast}}\right.$ Messgeräte GmbH Deutschland, Oberthulba, Germany) and analysed (Cardio-Pulmonale Funktions-Diagnostik Software, nSpire Health GmbH, Oberthulba, Germany). Reference values for the absolute $\mathrm{VO}_{2} \mathrm{max}$ for untrained healthy adults are between 2-3.5 1/min and 30-50 $\mathrm{ml} / \mathrm{kg} / \mathrm{min}$ for the relative $\mathrm{VO}_{2}$ max depending on age and gender (Fletcher et al. 1995). After every completed exercise step of the graded exhaustion test, trained staff collected a small blood sample of $20 \mu \mathrm{l}$ within capillary tubes from the ear lobe. Samples were analysed via lactate meter BIOSEN S-Line (EKF Diagnostic, Cardiff, England) and evaluated via the Software Laktauswertung Version 2.08.2010 (German Sport University Cologne, Institute of Cardiology and Sports Medicine, Cologne, Germany). 
At the end of the medical check-up, subjects rated their own fitness level and gave information about their activity in sports in a medical anamnesis history questionnaire (Jedlicka et al. 2018). In the present study, the following three questions were used and consisted of a Likert-type scale (range 1-10) with response options from $1=$ very bad to $10=$ excellent: "How do you subjectively rate your current health condition/quality of life/fitness level specific to your endurance performance on a scale from 1 to 10?" Furthermore, the medical anamnesis history questionnaire includes information about drug use, smoking habits and involvement in sports or leisure time activities. Multiple answers were possible to report the involvement in sports.

\section{Carrisma Risk Based on the Procam Algorithm}

The overall cv risk scoring for stratification can be calculated with different algorithms (Assmann et al. 2002, De Backer et al. 2003, Conroy et al. 2003, Gohlke 2012, Kones 2011). In summary, the main differences between the score systems are the ESC SCORE (Systematic Coronary Risk Evaluation) and the PROCAM (PROspective CArdiovascular Münster) algorithm evaluate risk factors slightly differently. The risk of hypertension-dependent (fatal) events, such as stroke, aortic rupture and death due to peripheral vascular disease, is in addition to cardiac death - only in ESC-SCORE. In contrast, the risk of cholesterol-dependent events, such as heart attacks, is better represented in the PROCAM algorithm. Depending on the severity of the risk profile, it is worth a calculation with both systems. The calculation of the CARRISMA risk value, based on the PROCAM score, is an advanced, modern appraisal tool, since this, in addition to the usual parameters, considers additional lifestyle information (e.g., physical activity, number of smoked cigarettes instead of smoking yes/no, BMI) for predicting non-fatal and cv events integrated over the next decade. Risk stratification allows individuals to be identified by a preventive approach.

Patients older than 45 years with more than one risk factor should have a risk stratification. If the risk for cv events in 10 years is $20 \%$ or the cv mortality risk exceeds $5 \%$, it may be an indication for drug therapy, as it indicates a high risk status (Gohlke et al. 2007, Gohlke 2012). However, this may be dependent be different from the age of the specific person and needs to be considered individually.

The parameters for calculating the total risk are age, sex, BMI, abdominal girth, information concerning physical activity and lifestyle, and blood pressure. For smokers, additional parameters are number of smoked cigarettes per day, blood lipids and family medical history.

In this study, the Carrisma risk ${ }^{\circledR}$ based on the Procam algorithm was calculated as it presents an improvement in cv risk management and adds further qualitative and quantitative parameters to the existing basal scores (software Carrisma ${ }^{\circledR}$ test version 2.0.0.1347) (Gohlke et al. 2007). 


\section{Statistical Analyses}

All data are expressed as mean and standard deviation of the mean, MIN for minimum values, MAX for maximum values, numbers and percentages. A correlation analysis of all variables, including the Carrisma risk score, is presented via Pearson and Spearman correlation coefficients, respectively. A multiple linear and stepwise regression analysis was performed to identify further parameters and determine single contribution for an optimization of the Carrisma risk algorithm. For identification and determination of single contribution, eight independent objective (relative personal fitness, endurance performance, maximal lactate) and subjective (perceived quality of life, health status, endurance, power and hours of weekly sport activity) variables were integrated in the analysis.

To analyze whether the regression model overall is significant, an F-test is performed. It tests whether the prediction of the dependent variable is improved by adding a specific independent variable.

Statistics with a value of $\mathrm{p}<0.05$ were considered significant (Bortz 2005). Statistical analyses were performed with SPSS Statistics 24 (IBM, Armonk, USA).

\section{Findings - Results}

Medical data and the incidence of overweight and obesity of the 110 subjects are illustrated in Figure 1 and Table 1.

Figure 1. Incidence of Overweight and Obesity

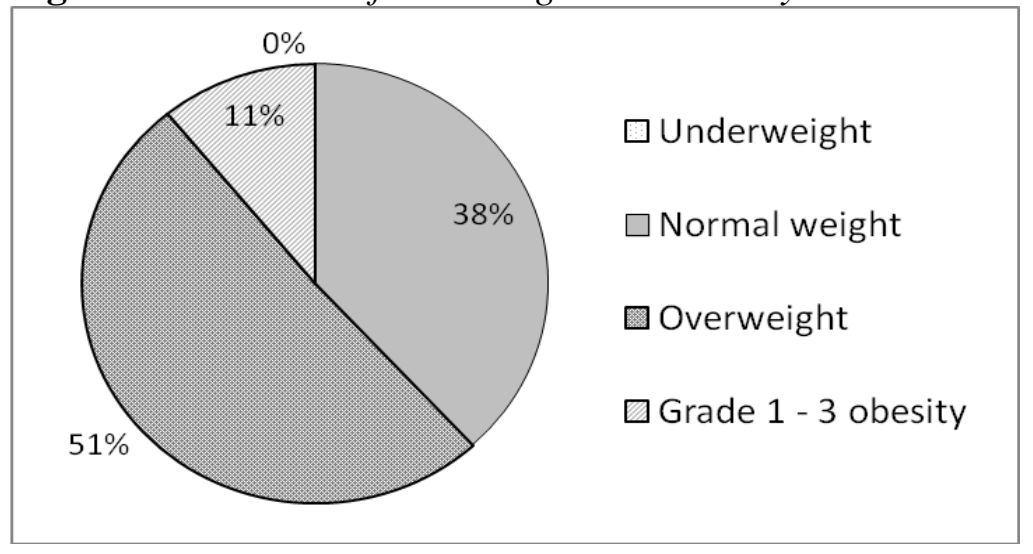

Forty-one subjects (37\%) are classified in the category hypertension degree 1 $\left(>140 />90 \mathrm{mmHg}\right.$ ) or worse. Mean values of pulse wave velocity are $7.5 \pm 1.5 \mathrm{~m} \mathrm{~s}^{-1}$ with an augmentation index AI @75 [90\% CI] of 14 $\pm 12 \%$. Thirty-one managers $(28 \%)$ need regular medication. Six of them take antihypertensive drugs, however two of these still have hypertensive blood pressure values. In the anamnesis medical history questionnaire, one subject reports using psychopharmaca after experiencing a burnout situation resulting from excessive, prolonged stress with the desire for professional reorientation. Of all subjects, $90 \%$ are nonsmokers. There are no subjects with diabetes, however 45 subjects $(41 \%)$ have symptoms of prediabetes. Thirteen participants (12\%) show signs of metabolic 
syndrome. Mean values are as follows: Triglycerides: $126 \mathrm{mg} / \mathrm{dl}$ (SD \pm 82.2$), \mathrm{HDL}$ : $57.6 \mathrm{mg} / \mathrm{dl}$ (SD \pm 17.5$)$, Hypertension: $130 / 84 \mathrm{mmHg}$.

Eighty-eight percent of the participants $(6$ subjects did not provide information in the anamnesis medical history questionnaire) stated to be physically active in sports (4 \pm 2.5 hours of sport per week), with $68 \%$ reaching, based on subjective reports, the international WHO activity guidelines. Most of the managers perform between 1 and $3(34 \%)$ or 3 and $6(45 \%)$ hours of sport per week, mostly being involved in endurance sports (69\%) (e.g. spinning, jogging, bicycling), strength training (33\%) (e.g. fitness, strength training) and individual sports (23\%) (e.g. mountain biking, gymnastics, dancing).

Regarding the performance diagnostics, all subjects except six reached individual age and sex specific cardiac exhaustion levels on the ergometer exercise test. Mean personal fitness is 229 watt $(\mathrm{SD} \pm 56.3)$ and relative personal fitness is $3 \mathrm{watt} / \mathrm{kg}(\mathrm{SD} \pm 0.8) .86$ of the 110 managers reached at least gender and age specific reference values for healthy untrained individuals concerning the PWC and performance. Mean absolute endurance performance (absolute $\mathrm{VO}_{2} \mathrm{max}$ ) is $3.0 \mathrm{ml} \mathrm{min}{ }^{-1}(\mathrm{SD} \pm 1.2)$ and relative endurance performance (rel. $\left.\mathrm{VO}_{2} \mathrm{max}\right) 35.5$ $(\mathrm{SD} \pm 13.4)$. Seventy-five percent achieved age and gender specific reference values of relative $\mathrm{VO}_{2} \max \left(\mathrm{ml} \mathrm{min}{ }^{-1} \mathrm{~kg}^{-1}\right)$ (Table 1).

Self-assessments revealed positive results (health status: 7.9 (SD \pm 2 ), quality of life: $8.4(\mathrm{SD} \pm 2.9)$, endurance: $5.8(\mathrm{SD} \pm 2.7)$, power: $6(\mathrm{SD} \pm 2)$ ), each of them out of 10 points (Table 1 ).

Table 1. Overview of Medical Data and Self-Reports

\begin{tabular}{|c|c|c|c|c|}
\hline Parameter & $\mathbf{M}$ & SD & MIN & MAX \\
\hline Age [vears] & 45.6 & 6.8 & 31 & 63 \\
\hline BMI $\left[\mathrm{m} \mathrm{kg}^{-1}\right]$ & 26.1 & 3.4 & 20 & 40 \\
\hline Pulse wave velocity $\left[\mathrm{m} \mathrm{s}^{-1}\right]$ & 7.5 & 1.5 & 5 & 12.5 \\
\hline Carrisma score [\%] & 2.6 & 3.8 & 0 & 27 \\
\hline Sports activity [hours per week] & 4 & 2.5 & 1 & 16 \\
\hline Personal fitness [Watt] & 229 & 56.3 & 140 & 320 \\
\hline PWC130 [Watt kg $\left.{ }^{-1}\right]$ & 1.7 & 0.6 & 0.3 & 3.0 \\
\hline PWC150 [Watt kg $\left.{ }^{-1}\right]$ & 2.1 & 0.7 & 1.4 & 3.7 \\
\hline Relative personal fitness [Watt $\mathrm{kg}^{-1}$ ] & 3 & 0.8 & 2 & 4 \\
\hline Max. Lactate $\left[\mathrm{mmol} \mathrm{l}^{-1}\right]$ & 8.5 & 3.2 & 3.7 & 14.4 \\
\hline Absolute $\mathrm{VO}_{2} \max \left[1 \mathrm{~min}^{-1}\right]$ & 3.0 & 1.2 & 1.6 & 4.8 \\
\hline Relative $\mathrm{VO}_{2} \max \left[\mathrm{ml} \mathrm{min}^{-1} \mathrm{~kg}^{-1}\right]$ & 35.5 & 13.4 & 18.8 & 53.0 \\
\hline Self-reported health status [points] & 7.9 & 2.9 & 5 & 10 \\
\hline Self-reported quality of life [points] & 8.4 & 2.9 & 4 & 10 \\
\hline Self-reported endurance [points] & 5.8 & 2.7 & 2 & 9 \\
\hline Self-reported power [points] & 6 & 2 & 2 & 10 \\
\hline
\end{tabular}

The correlation analysis including Carrisma score is presented in Table 2 (objective: relative personal fitness, relative endurance performance, maximal lactate; subjective: perceived quality of life, health status, endurance, power and hours of weekly sport activity). The Carrisma risk score showed significant associations $(\mathrm{p}<0.05)$ with relative personal fitness $(\mathrm{r}=-0.46)$, relative $\mathrm{VO}_{2} \max$ 
$(\mathrm{r}=-0.45)$, self-reported health status $(\mathrm{r}=-0.39)$, self-reported quality of life ( $\mathrm{r}=-$ $0.29)$ and self-reported endurance $(r=-0.40)$.

Table 2. Correlation Analysis

\begin{tabular}{|l|c|c|c|c|c|c|c|c|c|}
\hline Parameter & $\mathbf{( 1 )}$ & $\mathbf{( 2 )}$ & $\mathbf{( 3 )}$ & $\mathbf{( 4 )}$ & $\mathbf{( 5 )}$ & $\mathbf{( 6 )}$ & $\mathbf{( 7 )}$ & $\mathbf{( 8 )}$ & $\mathbf{( 9 )}$ \\
\hline $\begin{array}{l}\text { (1) Carrisma score [\%] } \\
\text { (2) Relative personal } \\
\text { fitness [Watt } \mathrm{kg}^{-1} \text { ] }\end{array}$ & $-0.46^{* *}$ & $-0.46^{* *}$ & $-0.45^{* *}$ & & $-0.39^{* * *}$ & $-0.29^{*}$ & $-0.40^{* *}$ & & \\
\hline $\begin{array}{l}\text { (3) Relative } \mathrm{VO}_{2} \mathrm{max} \\
{\left[\mathrm{ml} \mathrm{m}^{-1} \mathrm{~kg}^{-1} \text { ] }\right.}\end{array}$ & $-0.45^{* *}$ & $0.73^{* *}$ & & & $0.53^{* *}$ & & $0.48^{* * *}$ & $0.34^{*}$ & \\
\hline $\begin{array}{l}\text { (4) Max.Lactate } \\
\text { [mmol 1-1 }\end{array}$ & & & & & & & & & \\
\hline $\begin{array}{l}\text { (5) Self-reported } \\
\text { health status [points] }\end{array}$ & $-0.39^{* *}$ & $0.33^{*}$ & $0.50^{* *}$ & & & $0.58^{* *}$ & $0.55^{* *}$ & $0.55^{* *}$ & \\
\hline $\begin{array}{l}\text { (6) Self-reported } \\
\text { quality of life [points] }\end{array}$ & $-0.29^{*}$ & & & & $0.58^{* *}$ & & & $0.39 * *$ & $0.37 *$ \\
\hline $\begin{array}{l}\text { (7) Self-reported } \\
\text { endurance [points] }\end{array}$ & $-0.40^{* *}$ & $0.54^{* *}$ & $0.48^{* *}$ & & $0.55^{* *}$ & & & $0.60^{* *}$ & \\
\hline $\begin{array}{l}\text { (8) Self-reported } \\
\text { power [points] }\end{array}$ & & & $0.34^{*}$ & & $0.55^{* *}$ & $0.39 * *$ & $0.60^{* *}$ & & \\
\hline $\begin{array}{l}\text { (9) Sports activity } \\
\text { [hours per week] }\end{array}$ & & & & & & $0.37 *$ & & & \\
\hline
\end{tabular}

$* p<0.05$ (both sides), $* * p<0.01$ (both sides).

F-statistics of the regression analysis revealed a significant regression model $(\mathrm{F}(2,39)=6.995, \mathrm{p}=0.003)$.

The parameter relative personal fitness predicts Carrisma values to $15.8 \%$, and the self-assessed health status contributes with $6.8 \%$ to the final score. In total, both variables predict the risk score with $22.6 \%\left(R^{2}=0.26\right.$; corrected $\left.R^{2}=0.23\right)$. This results in the following prediction formula: $\mathrm{y}=\mathrm{m}^{*} \mathrm{x}$ is: $14.96-(2.33 \mathrm{x}$ personal fitness $[\mathrm{W} / \mathrm{kg}])-(0.78 \mathrm{x}$ rated health status [points]) (Table 3$)$.

Table 3. Regression Analysis for the Predictability of the Carrisma Risk Based on Procam

\begin{tabular}{|l|c|c|c|c|c|}
\hline \multicolumn{4}{|c|}{} & \multicolumn{3}{c|}{ 95\% CI } \\
\hline Variable & Standardized $\beta$ & SE & Sig. & Lower Limit & Upper Limit \\
\hline Rated health status [points] & -0.31 & 0.37 & 0.04 & -4.49 & -0.17 \\
\hline Relative personal fitness [W/kg] & -0.32 & 1.07 & 0.04 & -1.52 & -0.04 \\
\hline
\end{tabular}

Note: SE: Standard error, CI: Confidence interval.

\section{Discussion}

The objective of the present study was to assess the fitness and health status of high- ranked German senior business managers. The obtained results mostly demonstrate a better overall $\mathrm{cv}$ risk profile, including general health and fitness status, as compared to the age, sex and gender matched to the German broad population with the exceptions of overweight and prediabetes. These finding indicate that managers, suffering from high workload and stress levels, at least in part are capable of counterbalancing the negative health impacts. Furthermore, the regression analysis regarding the Carrisma risk identified two additional items to the already established algorithm that significantly improved the predictive value 
of the risk score. In the following, various cv risk factors, anthropometrical and medical parameters are listed in detail and compared to the broad German population, as well as to other studies with managers.

\section{Anthropometric and Medical Data}

The prevention of overweight, obesity and physical inactivity are key elements to limiting numerous chronic diseases (Robert Koch-Institut 2015). Although the average BMI of $26.1 \mathrm{~kg} / \mathrm{m}^{2}$ was lower than the average values of comparable cohorts within the German population at $26.7 \mathrm{~kg} / \mathrm{m}^{2}$ (Mensink et al. 2013), nevertheless $51 \%$ of the cohort were overweight and $11 \%$ were even obese, not revealing ideal results. Incidences in Germany in general reveal that overweight in men reaches $67 \%$ and in women: $53 \%$, obesity in men: $23 \%$, women in 24\%) (Robert Koch-Institut 2015). However, the BMI is only partly interpretable, since body composition was not considered in this study. Heidrick and Struggles (2014) found similar values with $48 \%$ of managers being overweight after evaluating the questionnaires of more than 658 German and German-Swiss CEOs. These differences between managers and the general German population may be due to a variety of factors.

First, the lower the socio-economic status, the higher the incidence of overweight and obesity (Robert Koch-Institut 2015). Secondly, a high percentage of managers have business meals more than twice a week or follow high-fat diets including dessert or snacks in between meals and thus have different dietary patterns than executives, e.g., according to a study of Kennedy (2003).

Blood pressure measurements in the present study illustrate that a slightly higher percentage (37\%) was affected by arterial hypertension compared to Germany's adult population (33\%) (Robert Koch-Institut 2015). Kennedy (2003) showed similar results with $36 \%$ hypertensive managers, while Hsu et al. (2016) published data between 11-22\%. The Kienbaum study (Hunziger \& Kesting 2004) reported via a survey with 142 CEOs that their job is associated with extremely high stress levels and workload. To summarize, 59\% worked daily at least 10 hours and were under permanent time pressure, including professional travelling activities more than twice per week (51\%). In addition, about one third were constantly accessible. The resulting lack of time for psychological and physical regeneration or private life might explain these health deficits and negative lifestyle patterns.

With respect to glucose metabolism, none of the investigated managers had manifest diabetes which was thus below the German average (9-13\%) according to the International Diabetes Federation (2006) or other studies (Hsu et al. 2016, Kennedy 2003). However, $41 \%$ of the managers vs. $5 \%$ of the German population were found be prediabetic (Little \& Sacks 2009, International Diabetes Federation 2006). This is of special interest, since Hsu et al. (2016) showed values between 13 and 18\% in Taiwan's executive-level employers. The results are in line with the high percentage of overweight in the present sample. Metabolic syndrome was detected in $12 \%$ of the subjects, which again was a considerably lower percentage than in the adult German population (20-25\%) (International Diabetes Federation 2006, Gupta \& Gupta 2010) as was the percentage of smokers (10\% in this study 
as compared to $25-30 \%$ in the common adult German population (Deutsches Krebsforschungszentrum 2015, Finger et al. 2013) and $16 \%$ in the study of Kennedy (2003).

More than 28 of the managers in this study were on regular medication, one of them being on psychopharmaca after having experienced a burnout situation resulting from work stress and leading to a desire for professional reorientation. Heidrick and Struggles (2014) reported a similar percentage with around 20\%, however a slightly higher medication intake in female managers $(25 \%)$, in the study of Kennedy (2003), even 56\% took daily medication.

On the basis of the above mentioned parameters, the overall $\mathrm{cv}$ risk for nonlethal events for the next 10 years in this cohort of managers was evaluated applying Procam score adding the Carrisma algorithm. Values above 20\% in the Carrisma risk indicate a high risk status (Gohlke et al. 2007, Gohlke 2012) which in this study was measured only in one participant, only three had values $\geq 10 \%$ and all others showed a low risk. In the PreFord Study, Gysan et al. (2004) reported that $86 \%$ of all subjects $(n=2,145)$ belonged to the risk group I (subjects with a low cv risk to suffer from an acute event $\leq 1 \%), 10 \%(n=256)$ to the risk group II (subjects with a medium cv risk to suffer from an acute event 1-5\%) and $4 \%(\mathrm{n}=96)$ to the risk group III (subjects with a high or very high $\mathrm{cv}$ risk to suffer from an acute event $>5 \%$ )

A regression model was calculated for the improvement of the predictive value of the Carrisma risk to identify further parameters influencing the cv risk model in managers. Out of eight, two variables had a significant influence on the overall Carrisma risk values and its predictive value: the self-rated health status and objectively measured personal fitness. Thus, it is suggested to modify the Carrisma risk algorithm by integrating these two parameters for future improved assessments of cv risk profiles. Seyedmehdi et al. (2016) examined similar research questions regarding the relationship of aerobic fitness with cardiovascular risk factors in firefighters and found comparable results. When summarizing, he stated that firefighters with greater aerobic fitness also revealed lower cv disease risk factors, underlining the importance of a healthy lifestyle and sufficient physical activity.

\section{Physical Activity and Fitness}

Regular physical activity has several positive effects on health and wellbeing at any age (Abu-Omar \& Rutten 2006, Borodulin et al. 2006). Abu-Omar and Rutten (2006) refer to a physically inactive lifestyle as a substantial risk factor for numerous diseases. In this study, data showed that most people were physically fit and reached gender and age matched capacities concerning their personal fitness and $\mathrm{VO}_{2} \max$ (Fletcher et al. 1995, Rost et al. 1989).

Eighty-eight percent of the managers were actively involved in sports, most of them between 2 and $61 / 2$ hours every week $(4 \pm 2.5 \mathrm{~h})$. The majority was engaged in endurance sport, classified as health-promoting concerning the cv system. Although working many long hours, $68 \%$, in comparison to about $61 \%$ of the broad German population (Lampert et al. 2012), reached the physical activity 
recommendations of $\mathrm{WHO}$, indicating that managers have a strong a focus on this important component of a healthy lifestyle.

The mean cardiorespiratory fitness in this investigation was $1.7 \mathrm{~W} / \mathrm{kg}$ (range 0.3-3.0) for $\mathrm{PWC}_{130}$ and $2.1 \mathrm{~W} / \mathrm{kg}$ (range 1.4-3.7). The cardiorespiratory fitness among adults between 18 and 64 years in Germany was assessed by Finger et al. (2013), measuring $1.22 \mathrm{~W} / \mathrm{kg}$ (range 1.2-1.24) for $\mathrm{PWC}_{130}$ and $1.63 \mathrm{~W} / \mathrm{kg}$ (range 1.6-1.7) for $\mathrm{PWC}_{150}$. Other values were published by Rost and Hollmann (1982) with $1.5 \mathrm{~W} / \mathrm{kg}\left(\mathrm{PWC}_{130}\right)$ and $2.0\left(\mathrm{PWC}_{150}\right)$ for men, respectively, which were clearly higher than measured in the study of Finger et al. (2013) but closer to the outcomes of this study. Since the PWC is standardized to bodyweight and more than $50 \%$ of these managers were overweight, it is interesting that PWC values still reached these high levels. It seems, at least in our study, as if managers from high-level management positions currently achieve a higher fitness level than the average, common German adult.

\section{Assessment of Self-Perceived Health}

Self-ratings of fitness and health have been proven as supportive tools by others in the past (Borodulin et al. 2006, Holtermann et al. 2015, Keith et al. 2014, Martinez-Gomez et al. 2012, Ortega et al. 2013). Managers in this investigation estimated their own health, quality of life, and endurance on a 10point Likert scale from 1 (very bad) to 10 (excellent). Mean values of all separate ratings were above average ( $>5$ points), pointing to general life contentment. Heidrick and Struggles (2014) investigated the self-perceived physical health status of managers with different grades and provided similar results (50\% "very good", 20\% "good", 26\% "satisfying" or "insufficient"), showing a general agreement to other literature in this field of research.

\section{Limitations and Strengths of the Study}

\section{$\underline{\text { Strengths }}$}

In the present study, a wide range of parameters were investigated to specify health and fitness in managers. To the best knowledge of the authors, this is the first investigation to provide data on objective physical performance measured via an incremental exercise exhaustion test and including a spiroergometry in highranked managers.

For standardized conditions and comparability of the results, all medical and performance tests were performed identically in all participating centers (Hamburg, Cologne, Munich). Data accuracy and reliability were enhanced by experienced, trained, medical staff in the centers. Furthermore, the grand sample size of 110 executives of first and second hierarchy and management level allows a high statistical power concerning the calculations (Bortz 2005).

\section{$\underline{\text { Limitations }}$}

The number of female executives was quite small; however, this reflects the real situation in high-ranked management positions. Data concerning physical 
activity are derived from questionnaires and not objectively measured. A further limitation of the study is the cross-sectional design of the study, as it cannot give information about possible cause-effect relationships. For future projects, it is recommended to analyze self-assessments of health and fitness with other assessment tools, such as the more validated Short-form 36 Questionnaire (SF-36) (Ware and Sherbourne 1992, McHorney et al. 1993) or the GPAQ (Bull et al. 2009). This observation can be a selection bias, because higher management positions require individuals who are physically capable and mentally robust.

\section{Conclusion}

In summary, the results showed that the managers of high-ranked positions of this study were of satisfying health, measured via various psycho-physiological parameters. Exceptions were the incidences of hypertension, prediabetes and overweight. Thus, it seems as if managers strive for a healthy lifestyle with sufficient physical activity. However, there is still a great demand to enhance healthy lifestyle patterns in the future, especially to reduce hypertension, prediabetes and overweight in executive employees. Higher management positions require individuals who are physically capable and mentally robust; stable physical and psychological well-being of employees and employers has beneficial effects for the success of a company.

It is recommended to integrate and apply the extension of CARRISMA's algorithm for cv assessment by two additional parameters - self-rated health status und personal fitness, measured in a bicycle exhaustion test - in the future.

The study delivers results for future projects regarding worksite health promotion in companies. Novel approaches, concepts and possible solution proposals might be developed for managers, which may be applied also to other employees in the future. At this point, corporate health management programs should be further improved, individualized and adapted so they can be implemented nationwide. Further research with comparable examinations should be conducted in medium and small-sized companies, executives and employees working from the middle and lower management level and other employees, in particular female executives. Such programs will not only maintain or improve the individual health or well-being, but will also enhance the economic success of companies.

\section{Acknowledgements}

This trial has been registered at the German Clinical Trials Register (DRKS registration number: DRKS00010986). The study was approved by the local ethics committee of the German Sport University Cologne, Germany (Number: 099-2016). 


\section{Conflict of Interest}

The authors have no conflict of interest to report. This research received no specific grant from any funding agency in the public, commercial, or not-for-profit sectors.

\section{References}

Abu-Omar K, Rutten A (2006) Sport oder korperliche Aktivitat im Alltag? Zur Evidenzbasierung von Bewegung in der Gesundheitsforderung (Physical activity and health. Evidence for the health benefits of different physical activity promotion concepts). Bundesgesundheitsblatt, Gesundheitsforschung, Gesundheitsschutz 49: 1162-1168.

Assmann G, Cullen P, Schulte H (2002) Simple scoring scheme for calculating the risk of acute coronary events based on the 10-year follow-up of the prospective cardiovascular Munster (PROCAM) study. Circulation 105: 310-315.

Borodulin K, Laatikainen T, Salomaa V, Jousilahti P (2006) Associations of leisure time physical activity, self-rated physical fitness, and estimated aerobic fitness with serum C-reactive protein among 3,803 adults. Atherosclerosis 185: 381-387.

Bortz J (2005) Statistik: Für Human- und sozialwissenschaftler. Vienne: Springer.

Bull FC, Maslin TS, Armstrong T (2009) Global physical activity questionnaire (GPAQ): nine country reliability and validity study. Journal of Physical Activity \& Health 6: 790-804.

Chobanian AV, Bakris GL, Black HR, Cushman WC, Green LA, Izzo J, et al. (2003) The Seventh Report of the Joint National Committee on Prevention, Detection, Evaluation, and Treatment of High Blood Pressure: the JNC 7 report. JAMA 289: 2560-2572.

Conrads C (2015) Deutschland führt?! Bundesweiten Befragung aller Branchen zum Thema Leadership (Germany leads?! Nationwide survey on the topic leadership in Germany). Information Factory Deutschland $\mathrm{GmbH}$, Nürnberg, Germany. Forum Management Starnberg.

Conroy RM, Pyorala K, Fitzgerald AP, Sans S, Menotti A, de Backer G, et al. (2003) Estimation of ten-year risk of fatal cardiovascular disease in Europe: the SCORE project. European Heart Journal 24: 987-1003.

De Backer G, Ambrosioni E, Borch-Johnsen K, Brotons C, Cifkova R, Dallongeville $\mathrm{J}$, et al. (2003) European guidelines on cardiovascular disease prevention in clinical practice. Third Joint Task Force of European and Other Societies on Cardiovascular Disease Prevention in Clinical Practice. European Heart Journal 24: 1601-1610.

Deutsches Krebsforschungszentrum (German Cancer Research Center) (2015) Tabakatlas Deutschland 2015 (Tobacco Atlas Germany 2015). Lengerich, Westf: Pabst Science Publishers.

Finger JD, Krug S, Gosswald A, Hartel S, Bos K (2013) Kardiorespiratorische Fitness bei Erwachsenen in Deutschland: Ergebnisse der Studie zur Gesundheit Erwachsener in Deutschland (DEGS1) (Cardiorespiratory fitness among adults in Germany: results of the German Health Interview and Examination Survey for Adults (DEGS1)). Bundesgesundheitsblatt, Gesundheitsforschung, Gesundheitsschutz 56: 772-778. 
Fletcher GF, Balady G, Froelicher VF, Hartley LH, Haskell WL, Pollock ML (1995) Exercise standards. A statement for healthcare professionals from the American Heart Association. Writing Group. Circulation 91: 580-615.

Gohlke H (2012) Primarpravention der koronaren Herzerkrankung: Was nutzen die Risiko-Scores? (Primary prevention of coronary artery disease: is there a role for risk scores?). Herz 37: 75-80.

Gohlke H, Winter M, Karoff M, Held K (2007) CARRISMA: a new tool to improve risk stratification and guidance of patients in cardiovascular risk management in primary prevention. European Journal of Cardiovascular Prevention and Rehabilitation: Official Journal of the European Society of Cardiology, Working Groups on Epidemiology \& Prevention and Cardiac Rehabilitation and Exercise Physiology 14: 141-148.

Grannemann U, Seele H (2016) Führungsaufgabe Change: Eine Roadmap für Führungskräfte in Veränderungsprozessen (The Change of Leadership: A roadmap for executives). Wiesbaden: Gabler.

Gupta A, Gupta V (2010) Metabolic syndrome: what are the risks for humans? Bioscience Trends 4: 204-212.

Gysan DB, Latsch J, Bjarnason-Wehrens B, Albus C, Falkowski G, Herold G, et al. (2004) The PreFord Study. A prospective cohort study to evaluate the risk of a cardiovascular event (overall-collective) as well as a prospective, randomized, controlled, multicentre clinical intervention study (high-risk-collective) on primary prevention of cardiovascular diseases in the Ford Motor Company employees in Germany. Zeitschrift für Kardiologie 93(2): 131-136.

Heidrick and Struggles (2014) Die Gesundheit deutscher Führungskräfte (Health status of German's executives). Max-Grundig-Klinik, Bühl im Schwarzwald, Germany. Retrieved from https://bit.ly/2IacEvf.

Holtermann A, Marott JL, Gyntelberg F, Søgaard K, Mortensen OS, Prescott E, et al. (2015) Self-reported cardiorespiratory fitness: prediction and classification of risk of cardiovascular disease mortality and longevity--a prospective investigation in the Copenhagen City Heart Study. Journal of the American Heart Association 4, e001495.

Hsu H-J, Chen D-R, Cheng Y, Su T-C (2016) Association of Psychosocial Work Hazards with Depression and Suboptimal Health in Executive Employees. Journal of Occupational and Environmental Medicine 58: 728-736.

Hunziger A, Kesting M (2004) "Work-Life-Balance" von Führungskräften-Ergebnisse einer internationalen Befragung von Top-Managern 2002/2003: Ergebnisse der Kienbaum-Studie: Zeitmanagement \& Worklife-Balance von Führungskräften (Work-Life-Balance of executives - results of an international survey of top managers 2002/2003). In Badura B, Schellschmidt H, Vetter C. (Eds.), Fehlzeiten-Report 2003. Springer, pp. 75-87.

International Diabetes Federation (2006) The IDF consensus worldwide definition of the metabolic syndrome. Retrieved from https://bit.ly/2IdCM4i.

Jamal M, Baba V (2000) Job stress and burnout among Canadian managers and nurses: an empirical examination. Canadian Journal of Public Health - Revue canadienne de sante publique 91: 454-458.

Jedlicka D, Petrowski K, Predel HG (under review) Validity and reliability of a new self-report instrument for measuring health, health-related quality of life and physical activity. Mental Health \& Prevention.

Jung J, Nitzsche A, Ansmann L, Ernstmann N, Ommen O, Stieler-Lorenz B, et al. (2012) Organizational factors and the attitude toward health promotion in German ICTcompanies. Health Promotion International 27: 382-393. 
Keil U, Fitzgerald A, Gohlke H, Wellmann J, Hense H (2005) Risikoabschätzung tödlicher Herz-Kreislauf-Erkrankungen. Die neuen SCORE-Deutschland-Tabellen für die Primärprävention (Risk assessment of fatal cardiovascular diseases. The new SCORE Germany tables for primary prevention). Deutsches Ärzteblatt 102(25): 1808-1812.

Keith NR, Clark DO, Stump TE, Miller DK, Callahan CM (2014) Validity and reliability of the Self-Reported Physical Fitness (SRFit) survey. Journal of Physical Activity \& Health 11: 853-859.

Kennedy A (2003) The CEO Health \& Wellness Survey. Corporate Wellness Program. Apollo Hospitals, Health Check-Up. The Deccan Chronicle.

Kones R (2011) Primary prevention of coronary heart disease: integration of new data, evolving views, revised goals, and role of rosuvastatin in management. A comprehensive survey. Drug Design, Development and Therapy 5: 325-380.

Lampert T, Mensink GBM, Muters S (2012) Korperlich-sportliche Aktivitat bei Erwachsenen in Deutschland. Ergebnisse der Studie "Gesundheit in Deutschland aktuell 2009" (Physical and sporting activity among adults in Germany. Results from the "German Health Update 2009" survey). Bundesgesundheitsblatt, Gesundheitsforschung, Gesundheitsschutz, 55: 102-110.

Lin YW, Lin YY (2014) A multilevel model of organizational health culture and the effectiveness of health promotion. American Journal of Health Promotion 29: 63.

Little RR, Sacks DB (2009) HbA1c: how do we measure it and what does it mean? Current Opinion in Endocrinology, Diabetes, and Obesity 16: 113-118.

Lundqvist D, Eriksson AF, Ekberg K (2012) Exploring the relationship between managers' leadership and their health. Work (Reading, Mass.) 42: 419-427.

Martinez-Gomez D, Gomez-Martinez S, Ruiz JR, Diaz LE, Ortega FB, Widhalm K, et al. (2012) Objectively-measured and self-reported physical activity and fitness in relation to inflammatory markers in European adolescents: the HELENA Study. Atherosclerosis 221: 260-267.

Masarei JR, Pyke JE, Pyke FS (1982) Physical fitness and plasma HDL cholesterol concentrations in male business executives. Atherosclerosis 42: 77-83.

McHorney A, Coleen A, Johne W, Raczek A (1993) The MOS 36-Item Short-Form Health Survey (SF-36). Medical Care 31: 247-263.

Meifert MT, Kesting M (2004) Gesundheitsmanagement-Ein unternehmerisches Thema? (Health Management-A topic for companies?). In MT Meifert, M Kesting (Eds.), Gesundheitsmanagement im Unternehmen (pp. 3-13). Berlin, Heidelberg: Springer Berlin Heidelberg.

Mensink GBM, Schienkiewitz A, Haftenberger M, Lampert T, Ziese T, Scheidt-Nave C (2013) Ubergewicht und Adipositas in Deutschland: Ergebnisse der Studie zur Gesundheit Erwachsener in Deutschland (DEGS1) (Overweight and obesity in Germany: results of the German Health Interview and Examination Survey for Adults (DEGS1)). Bundesgesundheitsblatt, Gesundheitsforschung, Gesundheitsschutz 56: 786-794.

Milatz F, Ketelhut S, Ketelhut RG (2015) Favorable effect of aerobic exercise on arterial pressure and aortic pulse wave velocity during stress testing. VASA. Zeitschrift fur Gefasskrankheiten 44: 271-276.

Ortega FB, Sanchez-Lopez M, Solera-Martinez M, Fernandez-Sanchez A, Sjostrom M, Martinez-Vizcaino V (2013) Self-reported and measured cardiorespiratory fitness similarly predict cardiovascular disease risk in young adults. Scandinavian Journal of Medicine \& Science in Sports 23: 749-757.

Plante A, Bouchard L (1996) Occupational Stress, Burnout, and Professional Support in Nurses Working with Dying patients. Omega 32: 93-109. 
Robert Koch-Institut (Ed.) (2015) Gesundheit in Deutschland (Health in Germany). Berlin: Robert Koch-Institut.

Rost R, Hollmann W, Heck H, Liesen H, Mader A (1982) Belastungsuntersuchungen in der Praxis. Grundlagen, Technik und Interpretation ergometrischer Untersuchungsverfahren (Exercise examinations in practice. Basics, techniques and interpretation of ergometric tests). Stuttgart, New York: Thieme Verlag.

Rost R, Heck H, Hollmann W (1989) Die Fahrradergometrie in der Praxis (Bicycle ergometry in the practical application). Leverkusen: Bayer.

Seyedmehdi SM, Attarchi M, Cherati AS, Hajsadeghi S, Tofighi R, Jamaati H (2016) Relationship of aerobic fitness with cardiovascular risk factors in firefighters. Work (Reading, Mass.) 55: 155-161.

Statistisches Bundesamt (2015) Statistisches Jahrbuch Deutschland 2015. Wiesbaden.

Tanaka H, Monahan KD, Seals DR (2001) Age-predicted maximal heart rate revisited. Journal of the American College of Cardiology 37: 153-156.

Ware JE, Sherbourne CD (1992) The MOS 36-item short-form health survey (SF-36). I. Conceptual framework and item selection. Medical Care 30: 473-483.

World Health Organization (2014) The top 10 causes of death: Fact sheet No. 310. Retrieved from https://bit.ly/1c9a3vO.

World Health Organisation (2015a) Diabetes Programme: About diabetes. Retrieved from https://bit.ly/2wrYIHw.

World Health Organisation (2015b) Obesity and overweight. Retrieved from https:// bit.ly/18pCdAN.

World Health Organization (2010) Global recommendations on physical activity for health. Retrieved from https://bit.ly/2I901Rh.

Zimber A, Hentrich S, Bockhoff K, Wissing K, Petermann F (2015) Wie stark sind Führungskräfte psychisch gefährdet? Eine Literaturübersicht zu Gesundheitsrisiken und arbeitsbezogenen Risiko-und Schutzfaktoren (Psychological endangerment of executives. A review about health risks and work-related risk factors). Zeitschrift für Gesundheitspsychologie 123-140. 
